\title{
Common Themes of Dedifferentiation in Somatic Cell Reprogramming and Cancer
}

\author{
G.Q. DALEY \\ Division of Pediatric Hematology and Oncology, Children's Hospital Boston and Dana-Farber Cancer \\ Institute; Department of Biological Chemistry and Molecular Pharmacology, Harvard Medical School; \\ Division of Hematology, Brigham and Women's Hospital; Harvard Stem Cell Institute; Howard Hughes \\ Medical Institute, Karp Family Research Building 7214, Boston, Massachusetts 02115
}

\begin{abstract}
With its hallmarks of unregulated cell proliferation and compromised differentiation, cancer represents a derangement of normal tissue homeostasis. A common set of pathways are activated in the transformed state, through either mutation or altered epigenetic regulation, and both heritable effects sustain the tumor. Classical views of cancer have invoked tissue dedifferentiation in the oncogenic process, whereas modern views embodied in the cancer stem cell hypothesis hold that cancer emerges from primitive tissue stem cells or specific progenitor populations that through mutations assume the self-renewal properties of stem cells. Recently, somatic tissues have been reprogrammed to a pluripotent state resembling embryonic stem (ES) cells by ectopic expression of a cocktail of transcription factors. The factors that drive reprogramming are oncogenes or have been linked to cellular transformation, suggesting that tumorigenesis and somatic cell reprogramming might indeed share common mechanisms of dedifferentiation.
\end{abstract}

Cancer is the quintessential clonal disorder, arising in a single cell that over time sustains a series of mutations in genes that govern cellular growth control, survival, and cell-cell interactions. During the last several decades, cancer researchers have focused on the nature of oncogenic mutations and their effects on the function of signal transduction pathways and states of cellular differentiation. The assembly of a catalog of oncogenic mutations has led to a host of effective anticancer agents directed against specific targets essential to the cancer cell.

More recently, a major goal of cancer research has been to define the specific cell of origin of cancer among the hierarchy of cells that constitute a specific tissue. It is well documented that tissues such as the skin, gut, and blood arise from a rare stem cell that self-renews and whose daughters undergo differentiation into a variety of specialized progeny that constitute the tissue mass. Cancers in these tissues might thus arise from mutations in the tissue stem cell itself, which already possess the machinery for continuous proliferation, or by alterations in the physiology of various stages of progenitor cells that have limited selfrenewal potential and would otherwise be committed to differentiation. The "cancer stem cell hypothesis" suggests that the cancer is sustained by a cell with stem-like properties of self-renewal and multilineage differentiation (Reya et al. 2001). The implication is that only rare cells within the tumor are critical to the maintenance of the tumor, and this has considerable implications for understanding the origins and treatment of malignancy.

The disease chronic myelogenous leukemia (CML) exemplifies many aspects of the cancer stem cell hypothesis (Daley 2004). The initial phase of the disease arises in the hematopoietic stem cell itself, by virtue of sustaining the Philadelphia chromosome translocation, but the more aggressive blast crisis stage appears to arise by mutation in more differentiated cells such as the granulocytemacrophage progenitor (GMP) (Jamieson et al. 2004). Whereas normal GMPs lack self-renewal potential, the leukemic GMPs of blast crisis CML have activated a gene expression program that mimics that of hematopoietic stem cells, which entail heightened function of $\beta$-catenin. Analysis of cases of human acute myeloid leukemia (AML) identifies the hematopoietic stem cell as the likely cell of origin of the initiating oncogenic translocations, but this population is essentially nonleukemic; the leukemic population is a more committed progenitor that has acquired additional cooperating oncogenic lesions (Miyamoto et al. 2000). Transformation by the MLL-AF9 oncogene associated with AML represents another model wherein expression in GMPs induces a self-renewal gene expression signature typical of hematopoietic stem cells, meaning that the tissue progenitors assume the replicative properties of the tissue stem cells (Krivtsov et al. 2006). Accumulating evidence in animal models of solid tumors suggests that the transit-amplifying cells of a tissue may frequently be the target population for oncogenic mutations, and the resulting cancer stem cell acquires features not only of selfrenewal, but of a dedifferentiated phenotype. Unraveling the molecular mechanisms of tumorigenesis, in the context of the specific target cells involved, will be critical for developing therapies that target cancer stem cells while salvaging the function of normal tissue stem cells.

The traditional notion that differentiated cells become "dedifferentiated" in cancer has been controversial, even more so since the wider appreciation that rare stem cells persist in many adult tissues and that these stem cells can 
act as a reservoir of oncogenic mutations. A rich literature has documented the reactivation of primitive programs of tissue gene expression, most notably the "cancer-testis antigens" that characterize a number of human tumors and that represent novel targets for cancer immunotherapy (Simpson et al. 2005). Recent studies of a number of highly malignant, poorly differentiated solid tumors have identified similarities in gene expression programs with embryonic stem cells (Ben-Porath et al. 2008), highlighting the fact that tumorigenesis can hijack embryonic pathways of tissue development. Indeed, morphogenetic changes exemplified by the epithelial-mesenchymal transition (EMT) of gastrulation are replayed in the evolution of primary tumors toward metastatic phenotypes and typically invoke the same players: the transcription factors snail, slug, and twist (Yang et al. 2004; Huber et al. 2005; Baum et al. 2008; Natalwala et al. 2008). In the context of mammary epithelial cells, EMT is associated with acquisition of stem cell markers and stem cell properties, including enhanced mammosphere formation and the capacity to form tumors, establishing a link between the EMT and acquisition of epithelial stem cell qualities (Mani et al. 2008).

Pathologists examining tumor tissue have long described the histologic appearance of various tumors as "dedifferentiated," reflecting the expansion of primitive less-specialized malignant cell types. In cases where cancers arise from primitive tissue stem cells that are otherwise rare but become morphologically apparent after extensive proliferation or from immature transit-amplifying progenitors, the description of dedifferentiation in fact reflects expansion of an undifferentiated cell population, rather than a dedifferentiated cell population that resides normally within the tissues. Dedifferentiation would apply only in cases where a more specialized cell type literally extinguishes expression of lineage-specific genes of specialized tissue function, in favor of expression of the more primitive program of tissue development, perhaps accompanied by a block in differentiation that makes the transition apparent. Indeed, it is likely, at least in some cancers, that alterations in differentiated progenitor populations result in reversion to the stem cell phenotype. Evidence for such a tissue transition must come from experimental systems that prospectively identify the cell of origin of the tumor as having already acquired markers of tissue specialization.

Insights into common mechanisms of dedifferentiation and cancer have arisen unexpectedly from studies of direct cellular reprogramming to the pluripotent state. Yamanaka's pioneering work has demonstrated that ectopic expression of a set of transcription factors (Oct4, Sox2, Myc, and Klf4) can reset the epigenetic state of differentiated somatic cells to pluripotency (Takahashi and Yamanaka 2006; Takahashi et al. 2007). The alternative pluripotency factors Nanog and Lin28 can be substituted for Myc and KLF4 to reprogram human somatic cells (Yu et al. 2007b). Of great interest, these reprogramming factors have all been implicated in tumorigenesis, raising the provocative hypothesis that cellular transformation and reprogramming entail common pathways and thus represent variations on similar biological themes. Examining the factors that mediate somatic cell reprogramming shows how dedifferentiation may be a more prominent element of tumorigenesis than previously appreciated.

Somatic cell reprogramming entails the erasure of gene expression programs characteristic of differentiated somatic cells and the reactivation of embryonic patterns of gene expression that are characteristic of the pluripotent state (Boyer et al. 2005, 2006). This genome-wide epigenetic transformation appears to be initiated by the Oct4 and Sox 2 transcription factors, which bind to a large common set of target genes and alter chromatin structure. Aberrant expression of either Oct 4 or Sox 2 is associated with deranged tissue homeostasis and tumorigenesis (Hochedlinger et al. 2005; Chen et al. 2008), and nanog misexpression is characteristic of germ cell tumors (Clark 2007). Myc is among the most well-documented oncogenes, known for its role in promoting immortalization of tumor cells in part through direct actions on telomerase (Wang et al. 1998). Klf4 is associated with colorectal tumors (Wei et al. 2006), and a close relative of Lin28, Lin28B, is associated with hepatocellular cancer (Guo et al. 2006). Activation targets of Oct4, Sox2, Nanog, and Myc are frequently expressed in poorly differentiated tumors (Ben-Porath et al. 2008), again revealing a common molecular circuitry in reprogramming and cancer.

The case of lin-28 in particular highlights a common pathway of reprogramming, dedifferentiation, and cancer. lin-28 was originally identified in C. elegans as a gene regulating the developmental timing of larval stages (Ambros and Horvitz 1984). Later, lin-28 was shown to reverse cell fates during vulval development, directly linking it to reprogramming (Euling and Ambros 1996). Recently, in studies aimed at understanding why certain microRNAs (miRs) were transcribed in embryonic stem cells but not expressed as functional miRs, we and other investigators showed that a prominent function of lin-28 is to inhibit the let-7 family of miRs by binding to the loop domain and inhibiting processing to the mature form (Newman et al. 2008; Piskounova et al. 2008; Rybak et al. 2008; Viswanathan et al. 2008). let-7 has been shown to function as a tumor suppressor in a variety of cancers, including breast, lung, and colon (Takamizawa et al. 2004; Akao et al. 2006; Yu et al. 2007a), likely by inhibiting the expression of known oncogenes such as Ras, Myc, and HMGA2 (Johnson et al. 2005; Sampson et al. 2007; Yu et al. 2007a). To date, only a closely related homolog of lin-28 (lin-28B) has been directly linked to hepatocellular carcinoma (Guo et al. 2006), a tumor type that has long been described as showing histopathologic dedifferentiation (Abelev 1971; Abelev and Lazarevich 2006). In unpublished studies, we have considerably extended the association of $l i n-28$ and $l i n-28 B$ with a number of human malignancies, strongly suggesting that modulation of processing of the let-7 family of tumor suppressors is a common feature of malignancy (S.R. Viswanathan et al., in prep.). lin- 28 is the only nontranscription factor to date to be implicated in reprogramming of human somatic cells to pluripotency (Yu et al. 2007b). Understanding precisely how lin-28 functions in somatic cell reprogramming and tumorigenesis, whether by direct effects on let-7 processing or perhaps other mechanisms such as mRNA stability (Bagga et al. 2005; Balzer and Moss 2007; Chendrimada et al. 2007), will shed light on how the dedif- 
ferentiation that is so evident in somatic cell reprogramming might also underlie tissue metaplasia, dysplasia, and tumor formation.

The predominant target cell for reprogramming studies has been the fibroblast, a motile mesenchymal cell type. Following ectopic expression of reprogramming factors, fibroblasts assume properties of epithelial cells, with tight cell-cell association through gap junctions and expression of E-cadherin reminiscent of mesenchymal-epithelial transitions in embryonic organ development. Interestingly, cells derived from gastric epithelia and keratinocytes appear to be reprogrammed more efficiently than fibroblasts (Aoi et al. 2008; Maherali et al. 2008). It will be revealing to probe how mediators of mesenchymal-epithelial transitions influence the reprogramming process.

Although there are common pathways activated during reprogramming and tumorigenesis, pluripotent stem cells and tumorigenic cells have important differences. A cardinal feature of pluripotent stem cells is the capacity to form teratomas, a distinct type of highly differentiated benign tumor that differs in fundamental ways from a malignancy (Lensch and Ince 2007; Lensch et al. 2007). Teratomas, by virtue of their predisposition to differentiation and tissue complexity, remain encapsulated and do not metastasize. Thus, whereas pluripotent cells are immortal, self-renew, and can form tumors, they fundamentally remain dependent on mitogenic signals in their environment and responsive to exogenous cues to differentiate. Teratocarcinomas, the malignant counterparts of teratoma, typically retain a degree of pluripotency but show more limited degrees of differentiation and behave more like malignant tumors in their potential for metastasis and tissue invasion. The critical distinctions between true cancer cells and reprogrammed somatic cells may be that reprogrammed cells remain genetically intact. Unraveling the critical distinctions - both genetic and epigenetic — between the pathways of tumorigenesis and somatic cell reprogramming promises to illuminate fundamental aspects of dedifferentiation that will be essential to understanding the safety of cell replacement products derived from pluripotent stem cells.

\section{ACKNOWLEDGMENTS}

Research in the author's laboratory was supported by grants from the National Institutes of Health (NIH), the NIH Director's Pioneer Award of the NIH Roadmap for Medical Research, and private funds contributed to the Harvard Stem Cell Institute and the Children's Hospital Stem Cell Program. G.Q.D. is a recipient of Clinical Scientist Awards in Translational Research from the Burroughs Wellcome Fund and the Leukemia and Lymphoma Society and is an Investigator of the Howard Hughes Medical Institute.

\section{REFERENCES}

Abelev, G.I. 1971. $\alpha$-Fetoprotein in ontogenesis and its association with malignant tumors. Adv. Cancer Res. 14: 295-358.

Abelev, G.I. and Lazarevich, N.L. 2006. Control of differentiation in progression of epithelial tumors. Adv. Cancer Res. 95: 61-113.

Akao, Y., Nakagawa, Y., and Naoe, T. 2006. let-7 microRNA functions as a potential growth suppressor in human colon cancer cells. Biol. Pharm. Bull. 29: 903-906.

Ambros, V. and Horvitz, H.R. 1984. Heterochronic mutants of the nematode Caenorhabditis elegans. Science 226: 409-416.

Aoi, T., Yae, K., Nakagawa, M., Ichisaka, T., Okita, K., Takahashi, K., Chiba, T., and Yamanaka, S. 2008. Generation of pluripotent stem cells from adult mouse liver and stomach cells. Science 321: 699-702.

Bagga, S., Bracht, J., Hunter, S., Massirer, K., Holtz, J., Eachus, R., and Pasquinelli, A.E. 2005. Regulation by let-7 and lin-4 miRNAs results in target mRNA degradation. Cell 122: $553-$ 563.

Balzer, E. and Moss, E.G. 2007. Localization of the developmental timing regulator Lin 28 to $\mathrm{mRNP}$ complexes, P-bodies and stress granules. RNA Biol. 4: 16-25.

Baum, B., Settleman, J., and Quinlan, M.P. 2008. Transitions between epithelial and mesenchymal states in development and disease. Semin. Cell Dev. Biol. 19: 294-308.

Ben-Porath, I., Thomson, M.W., Carey, V.J., Ge, R., Bell, G.W., Regev, A., and Weinberg, R.A. 2008. An embryonic stem celllike gene expression signature in poorly differentiated aggressive human tumors. Nat. Genet. 40: 499-507.

Boyer, L.A., Lee, T.I., Cole, M.F., Johnstone, S.E., Levine, S.S., Zucker, J.P., Guenther, M.G., Kumar, R.M., Murray, H.L., Jenner, R.G., et al. 2005. Core transcriptional regulatory circuitry in human embryonic stem cells. Cell 122: 947-956.

Boyer, L.A., Plath, K., Zeitlinger, J., Brambrink, T., Medeiros, L.A., Lee, T.I., Levine, S.S., Wernig, M., Tajonar, A., Ray, M.K., et al. 2006. Polycomb complexes repress developmental regulators in murine embryonic stem cells. Nature 441: 349-353.

Chen, Y., Shi, L., Zhang, L., Li, R., Liang, J., Yu, W., Sun, L., Yang, X., Wang, Y., Zhang, Y., et al. 2008. The molecular mechanism governing the oncogenic potential of SOX2 in breast cancer. J. Biol. Chem. 283: 17969-17978.

Chendrimada, T.P., Finn, K.J., Ji, X., Baillat, D., Gregory, R.I., Liebhaber, S.A., Pasquinelli, A.E., and Shiekhattar, R. 2007. MicroRNA silencing through RISC recruitment of eIF6. Nature 447: 823-828.

Clark, A.T. 2007. The stem cell identity of testicular cancer. Stem Cell Rev. 3: 49-59.

Daley, G.Q. 2004. Chronic myeloid leukemia: Proving ground for cancer stem cells. Cell 119: 314-316.

Euling, S. and Ambros, V. 1996. Reversal of cell fate determination in Caenorhabditis elegans vulval development. Development 122: $2507-2515$.

Guo, Y., Chen, Y., Ito, H., Watanabe, A., Ge, X., Kodama, T., and Aburatani, H. 2006. Identification and characterization of lin28 homolog B (LIN28B) in human hepatocellular carcinoma. Gene 384: 51-61.

Hochedlinger, K., Yamada, Y., Beard, C., and Jaenisch, R. 2005. Ectopic expression of Oct-4 blocks progenitor-cell differentiation and causes dysplasia in epithelial tissues. Cell 121: 465477.

Huber, M.A., Kraut, N., and Beug, H. 2005. Molecular requirements for epithelial-mesenchymal transition during tumor progression. Curr. Opin. Cell Biol. 17: 548-558.

Jamieson, C.H., Ailles, L.E., Dylla, S.J., Muijtjens, M., Jones, C., Zehnder, J.L., Gotlib, J., Li, K., Manz, M.G., Keating, A., Sawyers, C.L., et al. 2004. Granulocyte-macrophage progenitors as candidate leukemic stem cells in blast-crisis CML. $N$. Engl. J. Med. 351: 657-667.

Johnson, S.M., Grosshans, H., Shingara, J., Byrom, M., Jarvis, R., Cheng, A., Labourier, E., Reinert, K.L., Brown, D., and Slack, F.J. 2005. RAS is regulated by the let-7 microRNA family. Cell 120: 635-647.

Krivtsov, A.V., Twomey, D., Feng, Z., Stubbs, M.C., Wang, Y., Faber, J., Levine, J.E., Wang, J., Hahn, W.C., Gilliland, D.G., et al. 2006. Transformation from committed progenitor to leukaemia stem cell initiated by MLL-AF9. Nature 442: 818-822.

Lensch, M.W. and Ince, T.A. 2007. The terminology of teratocarcinomas and teratomas (author reply). Nat. Biotechnol. 25: $1211-1212$.

Lensch, M.W., Schlaeger, T.M., Zon, L.I., and Daley, G.Q. 2007. Teratoma formation assays with human embryonic stem cells: 
A rationale for one type of human-animal chimera. Cell Stem Cell 1: 253-258.

Maherali, N., Ahfeldt, T., Rigamonti, A., Utikal, J., Cowan, C., and Hochedlinger, K. 2008. A high-efficiency system for the generation and study of human induced pluripotent stem cells. Cell Stem Cell 3: 340-345.

Mani, S.A., Guo, W., Liao, M.J., Eaton, E.N., Ayyanan, A., Zhou, A.Y., Brooks, M., Reinhard, F., Zhang, C.C., Shipitsin, M., et al. 2008. The epithelial-mesenchymal transition generates cells with properties of stem cells. Cell 133: 704-715.

Miyamoto, T., Weissman, I.L., and Akashi, K. 2000. AML1/ETOexpressing nonleukemic stem cells in acute myelogenous leukemia with 8;21 chromosomal translocation. Proc. Natl. Acad. Sci. 97: 7521-7526.

Natalwala, A., Spychal, R., and Tselepis, C. 2008. Epithelialmesenchymal transition mediated tumourigenesis in the gastrointestinal tract. World J. Gastroenterol. 14: 3792-3797.

Newman, M.A., Thomson, J.M., and Hammond, S.M. 2008. Lin28 interaction with the Let-7 precursor loop mediates regulated microRNA processing. RNA 14: 1539-1549.

Piskounova, E., Viswanathan, S.R., Janas, M., LaPierre, R.J., Daley, G.Q., Sliz, P., and Gregory, R.I. 2008. Determinants of microRNA processing inhibition by the developmentally regulated RNA-binding protein Lin28. J. Biol. Chem. 283: 21310-21314

Reya, T., Morrison, S.J., Clarke, M.F., and Weissman, I.L. 2001. Stem cells, cancer, and cancer stem cells. Nature 414: 105-111.

Rybak, A., Fuchs, H., Smirnova, L., Brandt, C., Pohl, E.E., Nitsch, R., and Wulczyn, F.G. 2008. A feedback loop comprising lin-28 and let-7 controls pre-let-7 maturation during neural stem-cell commitment. Nat. Cell Biol. 10: 987-993.

Sampson, V.B., Rong, N.H., Han, J., Yang, Q., Aris, V., Soteropoulos, P., Petrelli, N.J., Dunn, S.P., and Krueger, L.J. 2007. MicroRNA let-7a down-regulates MYC and reverts MYCinduced growth in Burkitt lymphoma cells. Cancer Res. 67: 9762-9770.
Simpson, A.J., Caballero, O.L., Jungbluth, A., Chen, Y.T., and Old, L.J. 2005. Cancer/testis antigens, gametogenesis and cancer. Nat. Rev. Cancer 5: 615-625.

Takahashi, K. and Yamanaka, S. 2006. Induction of pluripotent stem cells from mouse embryonic and adult fibroblast cultures by defined factors. Cell 126: 663-676.

Takahashi, K., Tanabe, K., Ohnuki, M., Narita, M., Ichisaka, T., Tomoda, K., and Yamanaka, S. 2007. Induction of pluripotent stem cells from adult human fibroblasts by defined factors. Cell 131: 861-872.

Takamizawa, J., Konishi, H., Yanagisawa, K., Tomida, S., Osada, H., Endoh, H., Harano, T., Yatabe, Y., Nagino, M., Nimura, Y., et al. 2004. Reduced expression of the let-7 microRNAs in human lung cancers in association with shortened postoperative survival. Cancer Res. 64: 3753-3756.

Viswanathan, S.R., Daley, G.Q., and Gregory, R.I. 2008. Selective blockade of microRNA processing by Lin28. Science 320: 97100.

Wang, J., Xie, L.Y., Allan, S., Beach, D., and Hannon, G.J. 1998. Myc activates telomerase. Genes Dev. 12: 1769-1774.

Wei, D., Kanai, M., Huang, S., and Xie, K. 2006. Emerging role of KLF4 in human gastrointestinal cancer. Carcinogenesis 27: 23-31.

Yang, J., Mani, S.A., Donaher, J.L., Ramaswamy, S., Itzykson, R.A., Come, C., Savagner, P., Gitelman, I., Richardson, A., and Weinberg, R.A. 2004. Twist, a master regulator of morphogenesis, plays an essential role in tumor metastasis. Cell 117: $927-$ 939.

Yu, F., Yao, H., Zhu, P., Zhang, X., Pan, Q., Gong, C., Huang, Y., $\mathrm{Hu}, \mathrm{X}$., Su, F., Lieberman, J., et al. 2007a. let-7 regulates self renewal and tumorigenicity of breast cancer cells. Cell 131: $1109-1123$.

Yu, J., Vodyanik, M.A., Smuga-Otto, K., Antosiewicz-Bourget, J., Frane, J.L., Tian, S., Nie, J., Jonsdottir, G.A., Ruotti, V., Stewart, R., et al. 2007b. Induced pluripotent stem cell lines derived from human somatic cells. Science 318: 1917-1920. 


\section{$\$_{\mathrm{CSH}}^{\infty}$ Cold Spring Harbor Symposia SYMPOSIA on Quantitative Biology}

\section{Common Themes of Dedifferentiation in Somatic Cell Reprogramming and Cancer}

G.Q. Daley

Cold Spring Harb Symp Quant Biol 2008 73: 171-174 originally published online January 15, 2009 Access the most recent version at doi:10.1101/sqb.2008.73.041

References This article cites 43 articles, 12 of which can be accessed free at: http://symposium.cshlp.org/content/73/171.full.html\#ref-list-1

\section{License}

Email Alerting Receive free email alerts when new articles cite this article - sign up in the box at the Service top right corner of the article or click here. 